\title{
Romper géneros
}

To break genres

Pedro Serrano ${ }^{1}$

Resumen: Este ensayo sostiene que los caminos de la traducción se cruzan y forman diferentes configuraciones a medida que se avanza en ella y en el estudio de ella. También propone que la literatura traducida pertenece a la historia literaria de la lengua en la que aparece y, por tanto, debe formar parte de los estudios en esa lengua y esas literaturas. Comienza comparando diferentes traducciones del Arte poética de Horacio, pasa por la argumentación en filosofía de la ciencia de la preeminencia de la práctica sobre la teoría y afirma que traducir poesía es escribir poesía. Concluye proponiendo que la traducción literaria es un oficio de creación, crítica y teoría.

Palabras Claves: Traducción; autoría; práctica; teoría.

\begin{abstract}
This essay argues that the paths of translation intersect and form different configurations as one advances in it and in the study of it. It also proposes that translated literature belongs to the literary history of the language in which it appears and, therefore, should be part of the studies in that language and those literatures. It begins by comparing different translations of Horace's Ars poetica, goes through the argumentation in philosophy of science about the preeminence of practice over theory, and states that translating poetry is writing poetry. It concludes by proposing that literary translation is a craft involving creation, criticism, and theory.
\end{abstract}

Keywords: Translation; authorship; practice; theory.

${ }^{1}$ Universidad Nacional Autónoma de México (México). 


\section{Escarbando huellas}

Tomás de Iriarte inicia su «Discurso preliminar» a la traducción que hizo del Arte poética de Horacio, publicada en 1777 , con las siguientes palabras:

Muchos han comparado la Traducción con el Comercio; pero acaso serán pocos los que han penetrado toda la propiedad y exactitud que esta comparación encierra. Yo he considerado que así como el Comercio más útil y estimable es el que introduce en el Estado los géneros simples y de primera necesidad, así también la traducción más provechosa y loable es aquella que enriquece nuestro idioma con los buenos libros elementales de las Artes y las Ciencias. (Iriarte, 1777: III)

Iriarte, que se movía en términos y ambientes ilustrados, utiliza este marco comercial para adelantar las razones de la suya y discutir dos traducciones anteriores al español del poema de Horacio. A mí me interesa traerlo a colación por la relación que propone entre comercio y literatura, entre paños menores y textos elementales, entre lo interior o privado o pasteurizado o endogámico, y el trasiego o ensuciadero o enturbiamiento que el hecho mismo de la traducción inscribe en los objetos una vez que los vuelve de uso común, es decir que los pone en el mostrador de su comercio. Hay géneros para todos los gustos, entendido aquí género como «Tela o corte de tela», ${ }^{2} \mathrm{y}$ las escrituras literarias tienen la paradoja de ser especies saturadas en su propio acontecer que, sin embargo y a la vez, permiten el acceso e intervención de segundos y terceros agentes. De eso y no otra cosa está hecha la literatura, para desazón de quienes buscan fuentes originales, y la traducción es la mejor prueba de su renovada intendencia.

Pero antes de entrar en materia, quiero hacer una breve excursión por el poema de Horacio, que es, en sí mismo y por sus traducciones, un revolvente en las historias de la literatura, para desesperación ahora de quienes buscan especies originarias, incluida la tan contaminada de la literatura en español. Horacio fue una de las recurrencias continuas en el aprendizaje del latín, y por lo mismo hay una infinidad de traducciones de sus obras, de muchos niveles de calidad. Pero no es a eso a lo que me quiero referir, sino a su comercio en menudeo, a su operación pública, al pequeño detalle que en ella se puede ver de la relevancia de las operaciones que surgen en las traducciones, en el ensuciadero que surge cuando un verso es trasladado de una lengua a otra lengua. Eso servirá para ver de qué manera la traducción poética actualiza, expone y pone junto con pegado muchas cosas que sin su presencia ni siquiera notaríamos, haciendo volar por los aires las nociones en las que se pretende sustentar la exclusividad de los estudios litera-

${ }^{2}$ El Diccionario del Español de México la define así en su cuarta acepción (Género, s.d.). 
rios de una lengua y sus literaturas, sean estas las españolas, las inglesas o las caribeñas, haciendo de todo esto un sano pidginato.

Me centraré ahora en un detalle aparentemente mínimo pero que si ponemos nuestra atención en él veremos cómo cambia los paradigmas en los que nos movemos. Al activarse en español la traducción de un poema que estaba escrito en otra lengua (pero esto obviamente se puede trasegar de manera intercambiable a todas las lenguas y culturas) su estudio corresponde, por derecho propio, a la investigación de la literatura que se escribe en esa lengua, y no sólo, aunque también, a la de la lengua original. Como observó en un muy reciente tuit el escritor mexicano Emiliano Monge, «Cada vez que reviso la traducción de alguno de mis libros, pienso lo mismo: es absurdo que no se firme de manera común una obra que, de golpe, dejó de tener un solo autor» (Monge, 2021). Y si un libro tiene dos autores posee dos pasaportes y por ende, el libro tiene una doble nacionalidad. Ese libro hipogrifo pertenece, luego de este golpe de magia más que de suerte, a la literatura en la que de súbito emergió, y a aquella en la que alguna vez tuvo un solo autor.

Esa nueva autoría nos lleva a observar entonces que, por supuesto, su perpetradora ha tenido que tomar decisiones propias, ajenas a los esfuerzos de quien primero lo hizo aparecer, y dependientes de la lengua en la que reaparece. Es desde esta perspectiva, que observa la traducción de poesía al español como parte de los estudios de la literatura en español, que se puede uno preguntar, y también contestar, por qué Iriarte tradujo los hexámetros del Arte Poética a silvas, la métrica más flexible con la que podía contar el siglo XVIII, a diferencia de las traducciones anteriores, por ejemplo la de Vicente Espinel en 1665, que fue hecha en endecasílabos (de hecho, la introducción que Iriarte hizo a su traducción es una dura reconvención a los empeños hechos con anterioridad). $Y$ desde ese punto de observación podemos echar un ojo, y entender, algunas contemporáneas, como por ejemplo, la de Juan Antonio González Iglesias (Horacio, 2021), hecha enteramente en endecasílabo blanco, un verso perfectamente naturalizado en español - Piedra de sol, de Octavio Paz, por ejemplo, está escrito en endecasílabos blancos -, pero un género, para seguir con el símil de Iriarte, ya a estas alturas un poco gastado.

Uno podría preguntarse cómo se justifica esa decisión en una traducción del siglo XXI, y para eso es inevitable rascar en la historia métrica de la poesía en español contemporánea. En este caso, eso se explica fácilmente: González Iglesias pertenece a un grupo de poetas españoles que tiene como una de sus características principales, o marca de fábrica, escribir en endecasílabos blancos, pues ese es el verso machaconamente utilizado en mucha de la poesía española contemporánea. La explicación entonces, así como su decisión, no 
provienen del poema de Horacio, sino de la situación actual de la poesía en España, que tiene, como todas, algunas puntas, y muchos mesetazgos. Así que si nos fijamos, la apuesta de Iriarte en el siglo XVIII, si bien de una extensión mayor que el poema original, resulta más arriesgada que la de González Iglesias en el XXI, y en ese sentido es mucho más interesante, como poesía en sí, en español y ahora. Es cierto, por otro lado, que éste último respeta la regularidad versificatoria de Horacio, pero en lugar de arriesgarse a reproducir en español el ritmo de los hexámetros originales, por ejemplo, lo que hace es remedar en su traducción su propia manera de versificar (un verso que, como ya apunté, a estas alturas del español suena un poco gastado). En ese sentido hace que el poema no suene muy distinto a como sonaba cinco siglos antes, frente a la fiesta innovativa de Iriarte. Es decir, mientras que éste trató de actualizar para su época y normalizar para su tiempo el para sus oídos quizás machacón verso latino, y en ese sentido logró planos de significación poética que siguen siendo vigentes, González Iglesias no ha hecho más que arrastrar el agua a su molino, un molino de versos muy cansinos, pues es un hecho que mucha de la poesía que se escribe en España cae en esa prosodia sin cambios de fondo (otras áreas del español tienen sus propias peculiaridades, no todas halagüeñas) $Y$ aquí estamos, si nos paramos a pensar, ya de plano en una discusión sobre la poesía en español en nuestra época, en un terreno resba- ladizo, ensangrentado, sucio, y muy alejados de la seriedad y adustez que caracteriza a los estudios clásicos, pues la diferencia entre la silva de Iriarte y el endecasílabo blanco de González Iglesias no es tanto materia de los estudios en letras clásicas, sino de la poesía escrita en español.

En ese sentido, me parece, sería deseable que el verso latino de Horacio encontrara, en estos momentos tanto del español como de las reflexiones que sobre traducción se hacen, alguna vertiente menos familiarizante que la empeñada por González, no tanto por las razones que dan ciertas teorías contemporáneas sobre la traducción, que buscan hacer de quien traduce el rostro original del texto traducido, o realizar determinadas operaciones más relacionadas con otro tipo de agencias o intereses que con la escritura de poesía (porque de eso estamos hablando, ¿no?, de escritura de poesía), sino porque una traducción de poesía, desde esta perspectiva, está y debe estar en discusión o en consonancia con lo que se está escribiendo en un momento preciso en una lengua determinada. Si no, para qué se hace, más allá de la larga tradición de los machacones ejercicios escolares. En ese sentido, las tomas de decisiones de un traductor se leen, o se deberían leer, en el contexto en el que en dicha lengua se está escribiendo y por supuesto que no - para enfocarnos un poco en las teorías contemporáneas sobre la traducción que encandilan a algunos -, en la traducción como un acto ajeno a la escritura en sí, que es 
como el teórico Lawrence Venuti la considera, cuando afirma que las «traducciones extranjerizantes en inglés pueden ser una forma de resistencia en contra del etnocentrismo y del racismo, del narcisismo cultural y del imperialismo, en el interés de las relaciones geopolíticas internacionales» ${ }^{3}$ (Venuti, 1997: 16). Esto es pertinente si el traductor es un egresado de la Carrera de Relaciones Internacionales en el Colegio de México, que utiliza la traducción con fines operativos, legítimos por supuesto, pero no cuando de lo que estamos hablando es la práctica de la traducción literaria, que, repito, es escritura en sí, e involucrta por ello toda la complejidad creadora de un individuo. La propuesta de Venuti es muy atractiva desde el punto de vista teórico, pero un poco chirriante si lo que estamos leyendo es un poema, pues desplaza la acción de quien traduce a posiciones relacionadas, como él mismo señala, con temas tales como el etnocentrismo, el racismo, el narcisismo cultural, el imperialismo, la geopolítica y las relaciones internacionales, temas que por supuesto están en los hechos literarios, pero que no suceden en sí en el acto de la traducción, sino, si se quiere, se activan consecuentemente. Porque si bien no se trata de desactivar estos preceptos a la hora de traducir, no está de más tomarlos en considera- ción, como señala Mark Polizzotti al comentar esta conceptualización, si lo que queremos es juzgar una traducción. «El punto de Venuti dice Polizzotti - es que la traducción no debe ser usada para homogeneizar los puntos de vista de otras culturas, y que la "ilusión de transparencia” resultante de las prácticas actuales oscurece la contribución lastrada culturalmente del traductor» ${ }^{4}$ (Polizzotti, 2018: 59). Más adelante volveré sobre esto, primero en la lectura de una traducción de Erin Moure de Pessoa al inglés, y posteriormente en un apartado sobre la relación entre la teoría y la práctica literarias, pero poor ahora quiero hacer énfasis en el hecho de que la traducción literaria es un fenómeno que sucede dentro del ámbito de la literatura en la lengua a la que se está traduciendo, y que ahí y desde ahí debe ser considerada. ¿O vamos a ponernos a pensar en actos de colonización al ejercer la traducción de unos versos de Horacio para su lectura de hoy?

Para entender la crítica que hago a la traducción de González Iglesias, y ubicarla en un contexto más amplio, me voy a remitir a un comentario reciente del poeta y traductor argentino Jorge Fondebrider sobre la poesía española contemporánea. Dice Fondebrider que

\footnotetext{
${ }^{3}$ «Foreignizing translations in English can be a form of resistance against ethnocentrism and racism, cultural narcissism and imperialism, in the interest of democratic geopolitical relations».

${ }^{4}$ «Venuti's point is that translation must not be used to homogenize other cultural viewpoints and that the "illusion of transparency" resulting from current practices obscures the culturally weighed contribution of the translator».
} 
los cambios en la prosodia del castellano de una y otra parte del mundo han hecho que un poeta español esté más cerca de la tradición y tenga un mayor apego por las formas fijas que el que, grosso modo, tiene un poeta de las otras provincias de la lengua, sometidas no a un momento de «vanguardia», sino a muchos que, por las razones expresadas, España desconoce. (Fondebrider, 2020)

Aunque es cierto que buena parte de ella, y por las razones expresadas por él, no ha podido desapegarse de prosodias aprendidas y reiterativas, no toda la poesía que se escribe en España, aclaro, sigue esas huellas que Fondebrider rastrea con claridad. Pero, me temo, en el caso que estamos presentando sí que sucede, y sus palabra vienen muy bien al caso. Traducir en el siglo XXI los hexámetros de Horacio necesita de un verso que baile entre las contorsiones del hexámetro latino y las posibilidades métricas de la poesía que se escribe en español en el siglo XXI, y desde ahí debe criticarse, Es en ese sentido en que los endecasílabos blancos de González Iglesias suenan gastados, en español, digo, no en latín, y decir esto es ejercer la crítica literaria en y dentro de la literatura en español. Y alcanzar esta escritura requiere de un esfuerzo de mentalidad al que, me temo, González Iglesias, a pesar de su enorme y valiosísima erudición, diría Fondebrider, no ha tenido acceso. ¿Vemos entonces cómo estamos inmersos de lleno en los pantanosos terrenos de la escritura en español, y por lo tanto de los estudios literarios del español, cuandfo hablamos de traducción al español?

\section{Cuellos de botella}

Regresemos entonces a Iriarte. El poema de Horacio, en su traducción, comienza así:

Si por capricho uniera un Dibuxante

A un humano semblante

Un cuello de caballo, y repartiera

Del cuerpo en lo restante

Miembros de varios brutos, que adornara

De diferentes plumas, de manera

Que el monstruo en cuya cara

De una muger copiaba la hermosura,

En pez enorme y feo rematara;

Al mirar tal figura,

¿Dexarais de reíros...?

(Iriarte, 1777: 2)

Como se puede ver, el verso, si bien muy alejado del hexámetro clásico de Horacio, fluye perfectamente en español. No hay que olvidar que el Arte Poética de Horacio, además de un poema, es una preceptiva, y como tal hay que buscarle el mejor acomodo en los intereses e intenciones literarias de la Ilustración española - y aquí ya estamos en terrenos históricos, como pueden ver. Felix María de Samaniego, el otro gran fabulista de ese siglo, quien, nos hace saber Francisco Salas Salgado, criticó duramente la versión de su contemporáneo, tradujo los mismos versos de la siguiente manera:

Si a una cabeza humana, muy peinada a la moda y muy galana, 
le añadiera un pintor plumas de gallo

y un pescuezo de burro o de caballo;

si juntando las piezas desiguales

de varios animales

por último en el lienzo retratara

una mujer de lindo talle y cara

con alas de avestruz o de gallina

y cola de merluza o de sardina,

¿quién, amigos Pisones,

dejara de reírse a borbotones $?^{5}$

«Débiles copias», «bellos originales». ¿Notan, al comparar estas dos traducciones contemporáneas entre sí, lo que se estaba jugando entonces en los campos del lenguaje, en la versificación, en su eficacia?

Las vueltas que da la vida en la traducción pueden llegar a ser inconmensurables. Sin salir del ámbito de Horacio, por sólo dar otro ejemplo, su monumental «Oda XXX» fue traducida al español, entre otros, por Rafael Pombo en Colombia en el siglo XIX y cerrando el siglo pasado por Daniel Samoilovich y Antonio D. Tursi en Argentina (Horacio, 1998). A su vez, como nota al margen ilustrativa de las justas históricas de un poema en otra lengua y otra tradición, recientemente Peter France tradujo al inglés versiones de este mismo poema hechas cronológicamente al ruso por Mijaíl
Lomonósov en 1747, Gavrila Derzhavin en 1795, Alexander Pushkin en 1836 y Konstantín Bátyushkov en 1826, como se puede ver en el excelente ensayo sobre las transposiciones de este poema de Ilya Kutik (2005). Menciono esto para mostrar cómo, si siguiéramos únicamente esta línea de pesca, quién sabe dónde pararíamos. La Biblioteca de Babel de Borges, en realidad, de lo que está hecha es de traducciones, y es quizás por eso que, en ese cuento, a los estudios sobre traducción se les confina a los departamentos más oscuros, y se abandona a los traductores en mazmorras inhabitables. No voy a entrar, por ello, a los vericuetos que este poema monumental nos llevaría, no en ruso sino en español, pero sí voy a hacer un pequeño agregado, todavía ceñido al ámbito de Horacio y su Poética, para ver cómo en traducción todo es extensión y desenvolvimiento.

Gracias a González Iglesia supe que en «After Horace», un poema escrito a la salida de los llamados Troubles en Irlanda del Norte, que todavía en los años ochenta provocaban atentados en Londres, y en Irlanda del Norte huelgas de hambre tan fatales como olímpicamente ignoradas por Margaret Thatcher, el poeta irlandés Michael Longley decía lo siguiente:

\footnotetext{
${ }^{5}$ La traducción de Samaniego se publicó por primera vez en sus Obras completas (2001, Biblioteca Castro, Madrid), y por lo tanto no circuló en su época. Francisco Salas Salgado señala, sobre la de Iriarte, que «tampoco el otro gran fabulista del momento, Félix María Samaniego, la acogió con mucho entusiasmo. En efecto, un comentario de Iriarte vino a encender los ánimos del escritor vasco, quien, en un folleto titulado Observaciones sobre las fábulas literarias originales de D. Tomás de Iriarte, de 1782, arremete también contra esta traducción de la Epístola a los Pisones, considerándola «una de las más débiles copias de uno de los más bellos originales» (Salas Salgado, 2012: 58).
} 
We postmodernists can live with that human head Stuck on a horse's neck, or the plastering of multi-

Coloured feathers over the limbs of assorted

[animals

So that what began on top as a gorgeous

[woman

Tapers off cleverly into the tail of a black fish. (Longley, 1995)

Añado como dato curioso que la publicación de este libro, y de la poesía de Longley en general, se debe a uno de los más perspicaces editores de poesía en inglés, el también inusitado poeta escocés Robin Robertson, editor de poesía en Cape. Estos versos, que son en principio una denostación de la posmodernidad, y que por supuesto contestan y extienden a Horacio, pueden leerse, en su pertinencia, como una prolongación del surrealismo, aunque quizás, y de modo más incisivo aún, como respuesta a esas tres décadas de violencia en el ámbito de las islas Británicas.

De regreso a mi tema, incluyo la traducción al español de los cuatro primeros versos hecha por González Iglesias:

Nosotros los postmodernos sí podemos vivir

[con la cabeza

humana inserta en un cuello de caballo

o con esa argamasa de multi-colores

plumas que recubren los miembros de un

[surtido de animales.

(González Iglesias, 2016: 26)
A su versión, que aunque no del todo satisfecho dejo tal cual, añadiré los dos últimos versos de la estrofa original de Longley, que González Iglesias se abstuvo de traducir, para mostrar cómo los caminos de la traducción se abren a muchísimos canales de significación: «así que lo que comenzó por arriba como una mujer despampanante / se va estrechando astutamente en cola de pez negro». El pez enorme y feo de Iriarte, pasado luego de lo genérico a lo específico en mutilada o sinecdóquica cola de merluza o sardina (muy distintas en los dos peces, por lo demás) por Samaniego, termina reconvertida, trozada ya y generalizada, en la cola de pescado de Longley, que es también, si nos lo pensamos dos veces, profetización y personificación nada menos que de ese rabo abandonado a su suerte que es ahora Irlanda del Norte, estrago de la maleficencia del Brexit. Podemos ver hasta dónde, si nos dejamos conducir (del latín al español de la Ilustración, a la historia de la poesía en ruso, a los despotriques de Margaret Thatcher), la traducción, y en este caso únicamente del brazo juguetón de Horacio, puede irnos llevando de la mano. Por supuesto que Longley no pretendía esta implicación brexitiana, pero los poemas, en traducción o no, si son buenos, tienen mil maneras de actualizarse. $Y$ en estos momentos, qué mejor imagen para resaltar, un poco de pasada, el desgraciado lugar que ocupa Irlanda del Norte en el espacio geopolítico de nuestra época,y qué mejor imagen que ésta, perpetrada por Longley veinticinco años 
antes, para mostrar un absurdo que sin embargo es verdadero, y sin necesidad, valga sea dicho de paso, de las contorsiones propuestas por Venuti. La realidad de Irlanda del Norte representada en la actualización de esa versión de Longley, con sus múltiples pertenencias, es el ejemplo de lo que puede hacer el juego de vinculaciones que permite la traducción: un ente, una materia, una arena que pertenece simultáneamente a varios mundos; una realidad de la que el trueque, el intercambio, el comercio en suma, es uno de sus desdoblamientos conceptuales.

\section{Herencias emprendidas}

En un sutil y afilado ensayo, «Lingüística y literatura», Antonio Alatorre le dedica unos pocos párrafos a la traducción literaria, pero sus escuetas reflexiones en rápido deslizamiento están en realidad, para usar sus propias palabras, muy bien trabadas, así que me voy a detener un poco en ellas. Glosando a Edward Sapir, quien a su vez citaba a Benedetto Croce, Alatorre describe «la trabazón que hay entre la obra de arte literaria, expresión personal y única, y el lenguaje de que se sirve el artista, expresión plural y colectiva». «El único verdadero modo de leer a Homero es el griego en que están escritas la Odisea y la Ilíada», sigue Alatorre. E inmediatamente añade: «no hay ni habrá traducción de Li Po que comunique exactamente lo que Li Po les comunica a los lectores chinos». Si no fuera por los abismos que se abren entre cada una de estas refle- xiones, y a los que hay que volver, porque es lo que les da sentido, parecería que en ellas nos estamos empinando en uno de esos toboganes ciegos que apuestan no por la imposibilidad de la traducción, sino simple y llanamente por su inutilidad.

He tenido que separar las tres oraciones que componen esta cita e interrumpir su curso normal (que es donde se abren lo que llamo sus «abismos») para poder ver cómo su deslizamiento, aparentemente secuencial, en realidad está hecho de un salto triple en el que cada uno de los componentes responde a un impulso propio y se dispara hacia una significación autónoma. En el despliegue sabio y a la vez juguetón característico de la escritura de Alatorre - y también, agrego, de su enseñanza -, siempre hay meandros en los que vale la pena detenerse porque, como diría Cantinflas traduciendo a Hamlet según Tomás Segovia, «ahí está el detalle». Lo primero en que hay que fijarse es que la palabra que usa Alatorre para describir el vínculo entre quien escribe y lo escrito no implica un desenvolvimiento, sino una «trabazón», palabra que apunta en efecto a una juntura a la vez indisoluble y ensamblada, pero que también, en otra acepción, incorpora la noción de atoro. Antonio Alatorre, como profesor, siempre tenía un guiño detrás de sus afirmaciones, y siempre también un as bajo la manga. Así, en esta triple secuencia de trabes aparentemente claras y tan bien trabadas como para no permitir el menor resquicio, hay en realidad trampa de tahúr. 
Ya señalé el primer guiño en la palabra «trabazón». Fijémonos ahora en su segunda afirmación. En ella Alatorre señala que para leer, no en realidad la llíada ni la Odisea, sino a Homero (aquí el subrayado es mío), hay que leerlo en la lengua en que él escribió, lo cual, viniendo de este gran filólogo, es bastante obvio como para aceptarse como una afirmación simple. Si desdoblamos lo que está diciendo, nos daremos cuenta de que si bien es cierto que a Homero hay que leerlo en griego, lo que Alatorre está afirmando es que, no a Homero sino la Ilíada y la Odisea, en realidad se pueden leer en la lengua en la que se nos pegue la gana. Después de destrabar al autor de su escritura, el crítico termina su salto triple pasando de la lengua griega - que si bien usa caracteres distintos que el griego a fin de cuentas se escribe, como el español, en un sistema fonético - a la china, que lo hace en ideogramas, lo cual es una extrapolación de más difícil alcance. Pero es precisamente aquí donde está el tercer guiño de Alatorre, pùes lo que está haciendo no es referirse a los poemas de Li Po, como no lo era a las dos obras griegas, sino a lo que este poeta les comunica a sus lectores, lo cual efectivamente está para nosotros en chino si no sabemos chino.

Si nos fijamos, veremos que Alatorre en ningún momento se ha referido a lo que hay en las obras, sino a sus ocultas y sucesivas trabazones: es decir. a las junturas entre autor y obra, a la unión entre autor y lengua y a la vinculación entre autor y escritura. Esas tres relaciones son en efecto intraducibles. Pero lo que está haciendo Alatorre, poco a poco, es hacernos ver que eso que aparentemente pasa en las lecturas de los poemas originales no es lo que sucede en la traducción, porque en ellas hay siempre dos intermediarios: la persona que traduce esos textos, de Homero o de Li Po, y la lengua en la que están apareciendo esas palabras. Por eso inmediatamente añade: «Pero a continuación, suavemente y sin abandonar la línea de pensamiento de su venerado Croce, da Sapir un paso más, pues es un hecho - dice - que "la literatura se traduce, y en ocasiones con asombroso acierto"» (Alatorre, 2012:103). Lo que ha hecho Alatorre es dar ese mismo paso que dio Sapir, pero sin decir «agua va». Los meandros que recorre son parecidos a los que señala el poeta y traductor francés Yves Bonnefoy cuando dice que la respuesta a la pregunta de si se puede traducir un poema es por supuesto que no (Bonnefoy, 1990: 95), para seguir inmediatamente demostrando cómo es que los poemas, en efecto, se traducen, y en ocasiones con asombroso acierto. El ensayo de Alatorre no está dedicado a la traducción, sino como su nombre lo indica a las relaciones posibles de traducción entre los estudios de literatura y los de lingüística, pero es interesante que se haya detenido justo en el punto de inflexión en el que la traducción logra su parusía, pues algo parecido se da entre los estudios teóricos de la traducción y su práctica estudiosa. Lo mismo sucede, si regresamos a los originales, entre 
sus autoras y sus lectores, que están, en el acto de leerlos, traduciendo sus palabras a su propia comprensión, pero este ya es otro tema al que regresaré más adelante, pues todavía nos faltan algunos recovecos en este intricado camino en el que nos estamos internando, casi sin darnos cuenta. Así que regresemos al terreno de las más patentes traducciones, que son las de una lengua a otra, y que es el lugar por excelencia en el que la investigación sobre traducción como objeto de laboratorio se desarrolla. Pero antes de investigarla como objeto quiero intentar acercarme a ella como una actividad o acción, y para ello voy a recurrir a la reflexión de un par de poetas que están entre los que más han hecho por la traducción del en el siglo XX.

\section{De la teoría a la práctica}

El poeta y traductor belga Fernand Verhesen escribió que

Toda traducción se presenta, por naturaleza, como una interrogación sobre la actividad poética. Es también acompañamiento, en precisos y repetidos momentos, de ese encaminamiento en el que por razones posiblemente discernibles pero estrictamente personales participa el traductor. La elección que hace de traducir ciertos poemas no responde únicamente a una suerte de carencia compensatoria. Respondería más bien al deseo o a la necesidad que experimenta el traductor de tener la experiencia de otra identidad, no para enriquecer egoístamente la suya (aunque este enriquecimiento sea enorme), ni por ponérsela como un disfraz, sino para encontrar en sí la confirmación de que el acto poético no puede ocurrir, no puede vivirse, sino en la confluencia, en la encrucijada, de identidades múltiples y diversas. Por supuesto, cierto tipo de afinidades sensibles o mentales determinan muchas veces la elección de que obras traducir, pero puede muy bien ser suscitada por estimulantes divergencias. ${ }^{6}$ (Verhesen, 2003: 6)

Si eso les sucede a quienes traducen poesía, algo parecido les debe pasar también a sus lectores, en la lengua en la que están leyendo ese texto, y a eso que les pasa es a lo que llamamos experiencia poética. Pero para eso tenemos que regresar a la práctica escritural. T. S. Eliot, terminaba su reflexión sobre el verso libre afirmando que «sólo hay versos buenos, versos malos y caos» ${ }^{7}$ (Eliot,

\footnotetext{
${ }^{6}$ «Toute traduction se présente, par nature, comme une interrogation sur l'activité poétique. Elle est aussi accompagnement, à des moments précis et répétés, de ce cheminement auquel participe le traducteur pour des raisons éventuellement discernables mais strictement personnelles. Le choix qu'il fait de traduire certains poèmes ne répond nullement à une sorte de manque compensatoire, comme on l'a suggéré. Il répondrait plutôt au désir ou au besoin qu'éprouve le traducteur de faire l'expérience d'une autre identité, non pour enrichir égoïstement la sienne (encore que cet enrichissement soit énorme), ni pour s'en revêtir comme d'un déguisement, mais pour trouver en soi la confirmation que l'acte poétique ne peut advenir, ne peut se vivre, qu'au confluent, au croisement, d'identités multiples et diverses. Bien sûr, certaines affinités sensibles ou mentales déterminent souvent le choix des œuvres à traduire, mais il peut aussi bien être suscité par de stimulantes divergences».
}

${ }^{7}$ «There is only good verse, bad verse, and chaos». 
1978: 186). Es en su lectura donde vamos a ver si, en sí misma, una traducción es buena, es mala o es meramente un caos.

Como se podrá haber visto, al hablar de traducción y poesía sigo insistiendo en diferenciar y al mismo tiempo colusionar ambos campos de acción. Esta insistencia no es gratuita. Traducir poesía es escribir poesía (como leer poesía es escribir poesía). Quienes traducen un poema son poetas en el acto de la traducción de tal poema, independientemente de que quizás nunca hayan escrito un poema propio y de que quizás, también, nunca lo vayan a hacer. Detenerme en las traducciones al español de Horacio ha sido en ese sentido un ejercicio de crítica. Leerlas juntas pretende provocar una experiencia de lectura. $Y$ esta es una acción que, como toda acción poética, es profundamente misteriosa, por su proceso, por sus efectos, por su resultado. El factor inicial, como señala Verhesen, está en esa estimulación que, como también señala, viene casi siempre de una elección que se presenta como una interrogación que hay que resolver, y que es la que genera la acción creativa de la lectura, y posteriormente del acto de la traducción, al elegir tal poema. Pero el origen de esa elección no es del todo clara: se hace presente gracias al poema que se va a traducir pero no es en sí ese poema. Es decir, esa interrogación no está presente en la obra original, sino en el futuro al que se dirige la acción traductora. El pintor Frank Auerbach comentaba en una entrevista sobre el aprendizaje en las escuelas de pintura, que

\begin{abstract}
era importante comenzar con «alguna experiencia que es tuya propia e intentar grabarla en un idioma que sea tuyo propio, y no preocuparte en lo más mínimo por lo que te digan... Creo que la palabra clave es el tema - encontrar aquello que más te importa y perseguirlo.» (apud Lampert, 2015: 42)
\end{abstract}

Si sustituimos pintar por traducir, veremos que estamos hablando de lo mismo. Y si buscamos que quienes están aprendiendo a traducir alcancen unas traducciones verdaderas, es decir que pretendan ser buenas en tanto que poemas y en tanto que traducciones, lo importante es dejar que sean sus propias interrogaciones las que las conduzcan.

Ahora bien, la traducción implica, por su propio añadido, otro nivel de aprendizaje y demostración, relacionado una vez más con la acción creativa de la escritura poética. Valerio Magrelli, en un ensayo al que volveré más adelante, terminaba una reflexión sobre el ejercicio de la rima, un área de la traducción algo turbulenta a pesar de su aparente placidez, con una reflexión que va en este

\footnotetext{
${ }^{8}$ «It was important to begin with 'some experience that is your own and to try and record it in an idiom that is your own, and not to give a damn about what anybody says to you... I think that the key word there is subject - find out what matters most to you and pursue it».
} 
sentido de la acción poética que, como dice Verhesen, es vivido en el encuentro o choque de una multiplicidad de experiencias no discernibles de antemano y que, al irse adentrando en ella desemboca de nuevo, con una aparentemente mágica naturalidad, en el ejercicio de la traducción:

al retomar la noción de la poesía como un estado de ánimo y también un estado del lenguaje, he intentado definir al poeta como un ser híbrido, a medio camino entre un adivino (enigmista) y un poseso (envasato). Mejor: un «enigmista poseído» - expresión que creo muestra bien el estrechísimo parentesco que el hacer versos entretiene con los juegos de palabras, los acertijos, hasta llegar a los oráculos, las respuestas, las profecías (vaticinii). Entonces, si esto vale para quien escribe en versos, algo parecido le sucede a aquel que traduce tales versos, a partir de la intuición de Jorge Luis Borges según la cual no existiría ningún problema tan consustancial con las letras y con su modesto misterio como el que propone una traducción. ${ }^{9}$ (Magrelli, 2016)

La cita que Valerio hace de Borges es, en su discreta pero insondable incisión, contundente. No está de más subrayar que la palabra italiana para profecía es vaticinio, que viene de vate, poeta. En ese sentido, una estudiante que traduce un poema está ensayando ser poeta, así, en abstracto, y dicho en bruto, pero ser poeta de ese poema que en ese momento en particular está traduciendo. Como el pintor que emprende la representación de un modelo en la academia, según Auerbach, para alcanzar algo que no se quede en una mera copia inerte, la cual por su propia condición nunca va a poder llegar a existir per se, quien traduce un poema tiene que seguir su propia intuición, en la acción de la copia del original, si quiere alcanzar a crear algo que sea a la vez suyo, a la vez propio, y a la vez bueno. La traducción de poesía es una práctica escritural, y como tal, su resultado final es indiscernible para quien está ejerciéndola. Eliot señaló, décadas más adelante en su vida, que para los poetas «sólo existe el intentarlo» ${ }^{10}$ (Eliot, 2015: 19), pero esa es la apuesta, a la hora de la acción traductora, es decir de su práctica. El resultado ya se verá.

\section{De la práctica a la teoría}

Robert Ellrodt,profesor emérito de la Sorbonne Nouvelle, recordaba la siguiente afirmación hecha por un historiador de la traducción: «Es verdad que Michel Ballard ha descrito el re-

\footnotetext{
${ }^{9}$ «Riprendendo la nozione della poesia come stato d'animo e insieme stato di linguaggio, mi è capitato di definire il poeta come un essere ibrido, a metà strada fra l'enigmista e l'invasato. Meglio: un «enigmista invasato» - espressione che credo spieghi bene la strettissima parentela che il fare versi intrattiene con i giochi di parole, gli indovinelli, su su fino agli oracoli, i responsi, i vaticinii. Ebbene, se questo vale per chi scrive in versi, altrettanto lo è per chi quei versi traduce, in base all'intuizione di Jorge Luis Borges secondo cui non esisterebbe ningún problema tan consustancial con las letras y con su modesto misterio como el que propone una traducción».

10 «For us, there is only the trying».
} 
corrido del "traductólogo" como "el de un observador, que registra y estudia lo que parece ser un uso, o uno de los usos, entre aquellos que practican de instinto la traducción"» ${ }^{11}$ (el subrayado es mío) (Ellrodt, 2006: 65). Referirse a la práctica de la traducción como algo que se hace «por instinto», para separarlo de quienes estudian su ejercicio, es una de las técnicas con las cuales se pretende excluir las reflexiones hechas en la práctica de la reflexión teórica. ¿Qué querrá decir «practicar de instinto», me pregunto? ¿Algo así como «tocar de oído»? Yo considero, más bien, que es en la acción de la práctica en donde se debería sustentar cualquier posibilidad teórica. Para regresar a estos campos de la traducción como un objeto de estudio al que vale la pena acceder desde la conciencia de su práctica, me voy a referir ahora a un campo de conocimiento distinto del de la traducción. En un artículo aún no publicado sobre la «cinta de la vida», un concepto teórico elaborado por el paleontólogo Stephen Jay Gould para explicar la historia y evolución de ésta, el filósofo de la ciencia Alan C. Love empieza explicando que, en el tema que le atañe, «una metanarrativa tiene como intención interpretar o explicar las circunstancias de la vida y dar sentido a eventos aislados situándolos dentro del contexto de un patrón o meta general»12 (Love, 2001: 1). Si sustituimos aquí el término «vida» por «traducción» entenderemos claramente lo que quiero apuntar.

Parte de la motivación para moverse de las teorías a las prácticas - continúa Love - es que se han mantenido estables a lo largo de cambios dramáticos en las teorías científicas. [...] Se puede entender este argumento sobre el éxito de las practicas (más que de las teorías) en las estructuras de la realidad llamando la atención al hecho de que la investigación científica no siempre está organizada alrededor de un argumento explicativo basado en el razonamiento o desarrollo de una teoría central. En vez de eso, [el éxito de las prácticas] puede estar estructurado en formas de conocimiento que corresponden a metodologías experimentales y métodos para la generación y mantenimiento de entidades materiales (e.g. organismos modelo), un conocimiento descriptivo de patrones empíricos resultado de intervenciones en los experimentos y un conocimiento evaluativo capaz de medir y rastrear entidades y patrones con vistas a su utilidad en posteriores esfuerzos de investigación. ${ }^{13}$ (Love, 2021: 4)

\footnotetext{
${ }^{11}$ «Il est vrai que Michel Ballard a décrit la démarche du “traductologue” comme "celle d'un observateur, consignant et étudiant ce qui semble être un usage ou un des usages parmi ceux qui pratiquent d'instinct la traduction”».

12 «A metanarrative is intended to interpret or explain life circumstances and bring meaning to isolated events by setting them within the context of an overarching pattern or goal. It typically offers a framework for structuring and justifying the beliefs and practices of individuals, groups, and societies».

13 «Part of the motivation for shifting from theories to practices is that many practices have been stable across dramatic changes in scientific theories. For example, genetic approaches have been in use for more than 100 years despite major changes in our unders-
} 
Perdón por la extensión de esta cita, pero se justifica por lo lejano, en términos disciplinarios, de su procedencia - y temporales también, pero también por su pertinencia al referirnos a la traducción de poesía. Si bien es cierto que Love habla de cosas que sucedieron hace 600 millones de años, mientras que quienes se dedican a la traducción trabajan con fósiles de a veces apenas unos cuantos días de distancia, pero en el caso de la traducción también los métodos emitidos por las prácticas producen un éxito basado en conocimientos empíricos a los que hay que recurrir para cualquier discernimiento teórico posterior.

No es por un simple capricho que he recurrido a esta cita. Su inclusión, más bien, como se puede ahora ver, viene con una carga de profundidad. Muy al contrario de lo que pudiera parecer, una urgente pertinencia en los estudios literarios, diría Antonio Alatorre, particularmente en el campo de la traducción añadiría yo, es lo que la justifica.Y si en ciencia, en donde la teoría reina sobre todas las cosas, se están dado cuenta ahora de que la terquedad de la práctica es un gran correctivo a los despliegues y despegues teóricos, y de que su entusiasmo en la acción conduce muchas veces a resultados contrapuestos a los postulados de tales presunciones, en la traducción literaria su verificación puede comprobarse casi de inmediato, pues en muchos casos la validez no está dada por la aceptación de ningún círculo de pares teóricos o el prestigio de cualquier teoría académica, sino que es inmediatamente contrastada por su efectividad directa en el número de desdoblamientos y réplicas que genera esta o aquella traducción. De esto, aunque en términos más generales, es de lo que habla Antonio Alatorre en otro de los ensayos incluidos en el libro citado párrafos atrás, «Crítica literaria tradicional y crítica neo-académica», que fuera su discurso de entrada al Colegio Nacional de México. En ese ensayo, y me permitiré otra larga cita pues su explayamiento es contundentemente actual, Alatorre señaló en 1981, es decir hace 40 años, que

\footnotetext{
No hace mucho observaba Felix Guattari, que las muchas «modas teóricas» de hoy (y enumeraba el althusserismo, el estructuralismo, el lacanismo y varios más) son utilizadas por los universitarios «como si fueran dogmas religiosos» y recibidas con el mismo embeleso con que las colonias de tiempos pasados recibían lo producido en las metrópolis, todo lo
} 
cual, según él, está causando «más mal que bien», por la manera como se recibe. Yo siento lo mismo. Toda esa floración a que me he referido, esas grandes aventuras teóricas, esos brillantes documentos analíticos de la eterna lucha de Jacobo con el ángel, todo, todo eso está causando más mal que bien, por la manera como se recibe. Ciertas manifestaciones de la adopción embelesada de esas grandes modas me parecen casos diáfanos, no ya de progreso improductivo, sino de progreso contraproducente. Corruptio optimi prima. Del mejor vino se hace el peor vinagre. (Alatorre, 2012: 76)

Alatorre, cabe aclarar, no criticaba en su ensayo la pertinencia de las teorías. Trae por ejemplo a colación el término técnico «cláusula trimembre acentuada» que aparece en la novela Paradiso de José Lezama Lima, término del cual el poeta cubano por supuesto que se burla, por la degeneración en su uso, pero que, aclara Alatorre mefistofélicamente, proviene del seminario alemán de filología, del cual cabe decir que el propio Alatorre es heredero, y que aplicado a determinado tipo de versificación, como por ejemplo en «porque yo sé / la química, retórica, botánica» de la canción de Oscar Chávez «La Mariana», resulta perfectamente pertinente. Alatorre, por supuesto, no utiliza este ejemplo, pero tanto la popularidad de su uso en dicha canción como su pertinencia teórica en el estudio de la versificación, son incontestables. Es decir, no son las teorías las que están mal, sino el uso que de ellas se hace, al querer generalizar su aplicación a toda práctica.

Este énfasis en la práctica y su relación polémica con la teoría, que traje a cuento con sendos ejemplos, tomado uno de la ciencia y el otro de la filología, está también muy activo en el campo de la traducción literaria. En Sympathy for the Traitor, libro que ya mencioné, descrito por su autor en el mismo título como Un manifiesto, Mark Polizzotti señala que

generaciones actuales de teóricos académicos han revivido la Guerra Púnica entre fidelidad y felicidad en una forma más dura, maligna y politizada. Para muchos de estos teóricos la traducción a las principales lenguas occidentales constituye un acto de agresión en contra de la lengua y la cultura que están siendo traducidas. ${ }^{14}$ (Polizzotti, 2018: 58)

Nótense las referencia en ambos a la autoridad histórica (guerras púnicas en Polizzotti y actitudes coloniales en Alatorre), para mostrar improcedencias o impertinencias contemporáneas. Polizzotti centra su ataque precisamente en Venuti, a quien mencioné un poco antes:

\footnotetext{
${ }^{14}$ «Current generations of academic theorists have revived the Punic War between fidelity and felicity in a meaner, harsher, more politicized form. For many of these theorists, translation into major Western languages constitute an act of aggression against the language and culture being translated».
} 
A pesar de lo que Venuti afirma, un buen traductor trata no de promover cierta ilusoria invisibilidad sino más bien de infundir en el texto una cantidad apropiada de su propia personalidad, calibrada caso-por-caso, instancia-por-instancia: suficiente para darle a la traducción su propia distinción sin sofocar el original. ${ }^{15}$ (Polizzotti, 2018: 61)

Palizzotti contrapone, precisamente, lo que sucede en el terreno activo de la práctica con los resultados venidos desde la teoría. Para ello usa como ejemplo una comparación hecha por el propio Venuti de una traducción hecha por él mismo de un párrafo de 40 palabras de la escritora francesa Françoise Sagan frente a otra hecha por Irene Ash. La de Venuti tiene 42 palabras, señala Polizzotti, mientras que la de Ash sólo 24 pero, dice Polizzotti, «la comparación muestra, quizás de manera inadvertida, cómo Ash está mucho más cerca del tono y golpe de Sagan, en tanto que el ostensiblemente más preciso calco de Venuti, la hace sonar [a la traducción] aburrida» (Polizzotti, 2018: 78 ${ }^{16}$. Regresemos al principio. La práctica es en efecto intuitiva, en el sentido en que es resultado de un conocimiento que incorpora la intuición, pero para que funcione en su caminar incluye, siempre y forzosamente, una teoría de la traducción y una crítica del texto que se está traduciendo, que aunque éstas no se expliciten, están contenidas en esa medida dosis de personalidad que quien traduce infringe en su ejercicio.

\section{Transferencias de asombrosos aciertos}

Al comentar el ensayo de Antonio Alatorre en el que menciona la traducción, quise dejar para este momento la reflexión sobre los dos imposibles de la traducción, que son, según él, la individualidad del autor («expresión personal y única») y la abstracción del lenguaje («expresión plural y colectiva»). Estas dos entidades imposibles de traducir en su especificidad, entablan al encontrarse «una trabazón» cuyo resultado indudable es la obra literaria, realidad artística a la vez concreta e impersonal, y que es, paradójicamente, lo que sí se traduce. Para imaginarlo arquitectónicamente, digamos que en la juntura de esas dos trabes se abren unos resquicios por los que se cuela una luz y un aire que van a hacer posible la obra artística que es toda traducción literaria, y que, perdón por la redundancia pero al hablar de traducción siempre hay que redundar, que en un lenguaje nuevo un nuevo individuo alcance una nueva juntura entre personalidad y abstracción, que es obra única de quien tra-

\footnotetext{
${ }^{15}$ «Despite what Venuti asserts, a good translator aims not to promote some illusory invisibility but rather to infuse the text with an appropriate amount of his own personality, gauged on a case-by-case, instance-by-instance basis: enough to give the translation distinction without smothering the original».

16 «It shows, perhaps inadvertently, how much closer Ash comes to Sagan's tone and punch, while Venuti's ostensibly more accurate calque just makes it sounds dull».
} 
duce. La diferencia entre una escritura original y su traducción, como vio Walter Benjamin, es que ésta no se puede replicar, a menos que la intervención de quien traduce, para parafrasear a Polizzotti, se salga de toda proporción guardada, y esto significa desprender a la traducción del vínculo irrenunciable con el original y alcanzar la creación de un nuevo original - pero este es un tipo de escritura en el que ahora no entraré. Por ahora quiero ceñirme a estos dos espacios de imposibilidad y paradoja: la lengua y la persona, que para que surja una traducción tienen que trascenderse simultáneamente.

Empecemos por reflexionar qué sucede cuando la intervención se mantiene casi puramente en el nivel de las lenguas. En el delicioso ensayo «Un cuarteto de Yves Bonnefoy y algunas paradojas», que es en sí una lección de traducción, el poeta italiano Valerio Magrelli discurre sobre la traducción de los cuatro versos mencionados en el título. Observemos antes de seguir que tanto $\mathrm{Ma}$ grelli como Bonnefoy han hecho asombrosas traducciones al italiano y al francés, respectivamente, y han reflexionado profundamente sobre la práctica de la traducción de poesía. Es interesante que, para hablar de traducción de poesía, Valerio escogiera a uno de quienes más agudamente han escrito sobre traducción de poesía. El ensayo empieza poniéndonos sobre aviso de que los versos que va a traducir no son típicos de la producción de Bonnefoy, lo cual los hace especímenes peculiares, y que su particularidad consiste en que todos comparten una sola rima. La rima, cabe decir es uno de los conundros más difíciles de resolver a la hora de traducir, precisamente porque nos sitúa en la atmósfera enrarecida del lenguaje, con muy poco espacio y recursos para que se active la personalidad de una escritora. Yo personalmente a la hora de traducir trato de evitarla, excepto cuando es inevitable. Magrelli confronta a Vladimir Nabokov, uno de los escritores más reacios en sus reflexiones sobre la posibilidad de traducir poesía en quien se pueda pensar, y revisa su visión de la inconmensurabilidad de las lenguas, y desde ahí señala un problema de entrada entre el francés y el italiano: las rimas en francés caen siempre en palabras agudas y en italiano en graves o esdrújulas (en español las limitaciones son mayores, porque la mayoría de las palabras de esta lengua tienen acento grave. Como apuntaba Alatorre, la diferencia estructural de las lenguas, ese espacio común y social de cada una de ellas, condiciona de entrada la práctica del autor, y por supuesto la del traductor, si lo que quiere este último es levantar en una lengua lo que sucedió en otra.

Una de las maneras de resolver el problema de la propensión semántica que conlleva la rima en una lengua (por ejemplo «suerte»y «muerte» en español) es verla como un elemento que puede ser aislado en la práctica traductora, y sustituido con algún otro componente de la versificación. Pero en el caso del cuarteto de Bonnefoy, piensa Magrelli acerta- 
damente, la rima resulta un ingrediente ineludible, y entonces el poema tiene que encontrar su rima propia en la traducción. Lo que requiere de la inmersión total de quien traduce en las frías profundidades del vasto océano de su propia lengua para encontrar las perlas que hagan que su traducción rime. Magrelli, que es hijo de médico, al preparar la cocina de su traducción, se dio cuenta de que por ahí debía empezar. «Y esto, por cierto, es el factor crítico e interpretativo que toda traducción incluye y oculta, por cuan limitado esto pueda ser. Una vez establecido el programa a seguir (rima única), pasamos a sus posibles soluciones $»^{17}$ (Magrelli, 2016). Quiero hacer notar que al estar haciendo todo esto, Magrelli no ha visitado a sus hijos, pensado en su padre médico, o quejádose de la torcedura de pie que pudo haber tenido esa mañana. Es decir, no ha dejado que su mundo personal lo invada. Tampoco ha permitido que las potencias de significación en las que su personalidad mejor se mueve guíen su buceo. No ha salido ni un instante de la cocina en donde va a ejercer la práctica de la traducción y convirtiéndola en un espacio marino se ha dejado llevar por las corrientes de la propia lengua hasta encontrar sus perlas o su. 0 del laboratorio, que es muy parecido a una cocina o a un espacio marino. Lo cual no quiere decir que todos esos elementos no puedan introducirse de manera subrepticia en la elección de las palabras que va a hacer a la hora de traducir. Por supuesto que sí se van a inmiscuir, pero lo que no van a hacer es incluirse en el poema, porque entonces Valerio estaría montándose el poema de Bonnefoy para con las herramientas de la traducción llevarlo a otro lado. Más declaradamente, lo que sí va a tener frente a sí es todo el telar y fibras que componen la lengua italiana, que son sus materiales de trabajo. Para saber que eso tenía que hacer requirió de una conciencia crítica muy aguda de las operaciones que ese poema hacía en su lengua original. Pero ese espacio práctico, si lo pensamos, es el mismo que el que habitó el poeta al escribir su poema en la lengua en la que lo escribió. Es decir, Bonnefoy tuvo que resolver, en francés, limitaciones equivalentes a las que va a enfrentar Magrelli en italiano para hacer rimar su cuarteto. el ambiente enrarecido en el que ambos nardaron era el mismo, sólo que las perlas había que ir a buscarlas a lugares distintos. Las perlas encontradas son equivalentes pero distintas, otras y las mismas. A eso se referían Sapir y Alatorre cuando hablaban de asombrosos aciertos.

Utilicé la rima como ejemplo porque es el material más obviamente menos dúctil con el que se puede trabajar a la hora de traducir y porque nos sitúa en el espacio casi sin oxí-

\footnotetext{
${ }^{17}$ «E' questo, per inciso, il fattore critico e interpretativo che ogni traduzione include e cela, per quanto limitato esso possa essere. Una volta impostato il programma da seguire (rima unica), passiamo alle sue possibili soluzioni».
} 
geno de la lengua pura. Pero lo que es inescapable, si lo que se quiere hacer es poner un mismo poema en otra lengua, es que el material primero con el que se cuente sea la propia lengua, en los dos sentidos que esta expresión alcanza: la lengua del propio traductor y las singularidades de la lengua en la que se está traduciendo. Recapitulemos: en la traducción de un poema lo que sucede es la transferencia de una práctica poética original en una lengua con los elementos que la otra lengua le otorga en una nueva práctica. Suena un poco obvio pero, precisamente, en eso que parece obvio pero que no lo es radica la condición misma de lo que es una traducción, y en lo que ella consiste. Dicho en los términos más simples posibles, traducir un poema de una lengua a otra es hacer que ese poema sea de una manera simultánea, en palabras de Borges, «el otro, el mismo». En el caso de las traducciones, de este asombroso paso alquímico de lo otro a lo mismo (porque el poema sigue siendo ese poema) y de lo mismo a lo otro (porque el nuevo poema tiene una materialidad separada), de lo que se trata es de que lo que sucede en una lengua suceda en la otra. No lo que el poeta quiso que sucediera sino lo que está sucediendo en el poema. La escritura de ese mismo poema en otra lengua - porque también aquí, como en la práctica poética, hay que hablar de escritura - es donde se da el arte pequeña de la traducción, como la llamó Kate Briggs en uno de los libros recientes sobre traducción más sutiles que se pueden leer. Arte, porque la traducción es una práctica literaria hecha en una lengua determinada, y como tal debería estudiarse en las carreras de letras en esa lengua en particular, no sólo como especialización en los estudios de otras literaturas. Pequeña porque los cambios que impone en la realidad de eso que llamamos literatura pasan generalmente de manera imperceptible. Es importante subrayar esto porque lo pequeño o discreto de su presencia y realidad en tanto que materia factual de una literatura determinada ha hecho que, al no verla, distinguirla y registrarla, se hayan cancelado todos los espacios de estudio de traducción en los estudios de Letras Hispánicas en nuestra Facultad y se le tenga recluido como una especialización exclusiva en los de Letras Extranjeras. «iÉsta es una traducción! ¿Lo es? Estoy casi segura de que algo pasaría - algún ajuste en tu modo de leer sería muy probable que ocurriera - si me escucharas de repente insistir en que lo es» ${ }^{18}$ (Briggs, 2017: 48). En ese sentido este ensayo es a la vez reclamo y demostración de que la inclusión de los estudios de traducción en la carrera de Lengua y Literaturas Hispánicas de

18 «This is a translation! Is it? I feel sure that something would happen - some adjustment of your reading manner would be very likely to occur - if you were to hear me all of a sudden insisting that it is». 
la Facultad de Filosofía y Letras de la UNAM es urgente e indispensable. No verlo denota llanamente estrechez de miras. Y si se me apura, los argumentos que en él se desarrollan y los temas que toca, por lo que el estudio de esta pequeña arte desdobla y saca a la luz en su relación con el lenguaje y el individuo, son muestra de su pertinencia como materia optativa en las demás carreras de humanidades que en esa Facultad se imparten, pues la traducción es transversal y en ese sentido las toca, enriquece y acerca a todas, de la historia a la pedagogía y de la geografía a la filosofía.

\section{Inevitables contaminaciones}

La práctica de la traducción exige ceñirse a las disposiciones retóricas del poema en la lengua en que se escribió, que como ya mostré no pertenecen a la lengua propiamente dicha ni a la individualidad de quien lo escribió, sino a las pulsiones emocionales a las que quien escribió ese poema alcanzó en las particulares retorcederas de la lengua en la que lo escribió, para buscar activar esas mismas pulsiones en las disposiciones retóricas que la lengua en la que lo está traduciendo permite. Esto, por supuesto, abre el poema a una cantidad infinita de posibilidades, que como dice Walter Benjamin, están para la traducción de un poema pero no para un poema original, que es inamovible. Por lo mismo, el trabajo en la cocina de la traducción del que he estado hablando no implica que a quien traduce no la afecte lo que está haciendo, como si me- tida en un traje hermético entrara al laboratorio en donde no hay la menor posibilidad de contagio. Como los niños que llevan al nacer componentes genéticos no sólo del padre y de la madre, sino también, en diferentes grados, de todos los diferentes individuos que hayan tenido intercurso sexual con ambos miembros de la pareja, alguien que traduce un poema va a ser afectada en su propia organización mental por el mero hecho de internarse en el proceso y la práctica de la traducción de un poema determinado. En este sentido, los rastros que deja la traducción tanto en la literatura en la que reemerge un poema como en quien la ha intentado es equivalente a lo que señala la escritora Mehhan, especializada en temas de biología, sobre los últimos descubrimientos en cuanto a la historia genética de los individuos, que es más compleja que la simple adición aritmética de los genes del padre y de la madre. En su ensayo, Crist relata, con bases científicas y estadísticas, cómo una mujer puede heredar genes del feto que está engendrando, pertenecientes al padre, y hacerlos pasar posteriormente a una segunda descendiente. Así mismo, un hombre puede heredar genes de parejas anteriores, y transmitirlos a sus propios descendientes. Dice Crist:

\footnotetext{
El tema de con quien estamos relacionados, hace saltar también muchas de las intuiciones que tenemos sobre la ascendencia humana. Dejando de lado al ADN, si pensamos en nuestros antepasados únicamente como gente
} 
que procrearon unos con los otros, pronto nos topamos con una paradoja inescapable. ${ }^{19}$ (Crist, 2018)

La inclusión de los estudios de traducción en las historias de una literatura complica las cosas de una manera similar. ¿De quién hereda más como lector y luego como escritor Pablo Neruda, de Becquer o de Verlaine, leído en español en la antología de poesía francesa de Enrique Giner de los Ríos? ¿De verdad podemos permitirnos pasar por alto estas preguntas? Algunos de los estudiantes que pasaron por el Seminario de Poesía y Traducción gracias a traducir poemas empezaron luego a escribir poemas. En ese sentido, es imposible medir los ingredientes genéticos, paras usar el símil, que sus traducciones han depositado en sus procesos de pensamiento, la herencia que han dejado en su organismo. Y aunque el Seminario de Traducción y Poesía no pretendió nunca comprobar fehacientemente el grado de aprendizaje que cada una de ellas alcanzó en la traducción como creación, porque ese no ha sido su cometido, sí buscó poner una huella en el proceso de conocimiento de quienes asistieron en lo que respecta a los niveles crítico, teórico y práctico de la traducción de poesía. El poeta de origen alemán Michael Hofmann en la introducción a Impromptu, libro que recoge sus traducciones al inglés de los poemas de Gottfried Benn, señala que este escritor lo «ha influido, no sólo en primera instancia para traducirlo, sino también mientras lo traducía. A lo largo de los años, gracias en parte a Benn, mis propias oraciones se han vuelto más indeterminadas, mi lenguaje más musical, mi dicción más florida» ${ }^{20}$ (Hofmann, 2013). Entiendo por supuesto que empezar a rastrear estas cosas en toda una literatura cause escalofríos, pero no es razón para cerrar los ojos a su realidad. Y si esto le pasa a un poeta y traductor con el colmillo y la impiedad de Hofmann, ¿hasta dónde pudo llegar la traducción de los poemas que tuvieron a bien escoger quienes en este seminario se iniciaban en la práctica de la traducción?

Por supuesto, es imposible contestar esta pregunta, por lo menos no en este momento. Pasar por un seminario de poesía y traducción no le cambia la vida a nadie, supongo. Muchos habrán seguido en la academia dentro de nuestra universidad. Otros trabajarán en actividades de muy distinto tipo, alejados de la traducción y de la literatura. Habrá también quienes estarán siguiendo sus estudios, de literatura u otras disciplinas, en distintas ciudades y países. Pero la esperanza de cual-

\footnotetext{
${ }^{19}$ «The question of who we are related to also bucks intuition on much broader levels of human ancestry. Leaving DNA aside, if we think of our ancestors simply as people who procreated with each other, we soon run up against an inescapable paradox».

${ }^{20}$ «He has influenced me, not only to translate him in the first place, but also while translating him. Over the years, thanks in part to Benn, my own sentences have become more indeterminate, my language more musical, my diction more florid».
} 
quier enseñante, principalmente si se ha trabajado en la práctica, es que alguna huella haya quedado del trabajo realizado en común. Fue sobre estas suposiciones o bajo estos presupuestos que, cuando propuse el Proyecto de Investigación «La enseñanza de la traducción de poesía como creación literaria enfocada a la lengua de llegada», inmediatamente pensé en que valdría la pena que parte del proyecto incluyera el trabajo que se había realizado en el Seminario, y que de eso pudiera salir un libro en común. Pensé también que no se trataba de presentar lo que se estaba realizando en clase en estos momentos: hacerlo hubiera significado exponer a alumnos que están en formación a los crudos vientos del medio ambiente. En ese sentido, quienes estudian una licenciatura viven, en lo que a ésta respecta, arropados y protegidos dentro de un medio aislado, ajeno a cambios climáticos y a la exposición pública. De eso se trata la formación universitaria. Están allí para exponer sus ejercicios en clase, para confrontar sus ideas y sus aventuras con sus compañeros, para ser calificados por sus profesores, para sentirse exigidos pero también protegidos.

Pero eso debe ser sólo un escalón en el proceso de aprendizaje y exposición que toda formación conlleva. Llegado el momento, la vida pública y el aire fresco son sanos, qué remedio (ahora más que nunca somos todos conscientes de ello), y necesarios también para ver hasta dónde llega lo que hemos aprendido. Hay por supuesto quienes nunca salen de esos espacios protegidos. La aprehensión o la comodidad puede hacer que decidan optar por vivir siempre a la sombra de benevolentes cerezos y apacibles muros, exponiendo sus tímidos ofrecimientos a pares en igual de raquíticas condiciones y circunstancias. Pero no era eso lo que me interesaba. Había que buscar a la vez un punto intermedio y un medio diverso. Pensé entonces en reunir a algunas de quienes habían participado en el Seminario de Poesía y Traducción que impartí durante estos años e invitarlos a trabajar de nuevo en grupo, pero esta vez de una manera profesional. Muchos de ellos, además, habían tenido una primera experiencia de iniciación profesional formando parte de la Mesa de Traducciones del Periódico de Poesía, que llevaron Juan Carlos Calvillo en un primer momento y después Emma Julieta Barreiro. Con la ayuda de Mariela Castañeda, quien fue primero mi alumna y luego ha sido una brillante colaboradora tanto en el Seminario como en el Periódico de Poesía y varios otros proyectos, empezamos a preparar la investigación de la cual este libro es a la vez resultado y producto. Ambas cosas, adelanto, no son lo mismo. La inusitada forma en la que tuvimos al trabajar juntos en línea durante cuatro horas un día a la semana en los primeros meses de la pandemia, y la emoción de ver a un grupo de veinticinco pequeños rostros en pantalla de verdad involucrados y enganchados en la experiencia del otro en su traducción fue una de las experiencias de aprendizaje más enriquecedoras que he te- 
nido. La siguiente etapa, ya más focalizada, al trabajar de manera individualizada con cada una de ellas en el proceso de edición de sus ensayos para su publicación, que incluía desde la redacción y el uso de notas hasta la búsqueda de derechos de autor, se convirtió en un curso intensivo de profesionalización cuyo resultado tenemos ahora enfrente, y del cual ahora voy a hablar.

\section{Internship, prakticum, stage, tirocinio, estágio práctica: viaje al planeta traducción}

Como se pueden imaginar, al no haber ningún incentivo material y en algunos casos ni siquiera profesional, para la preparación del libro teníamos que reunir a un grupo de individuos cuyo interés en la traducción de poesía siguiera vivo por sí mismo. Consideramos que la convocatoria no debería estar reducida sólo a quienes siguieran vinculadas con la Facultad ni tampoco sólo a aquellas personas comprobadamente dedicadas a la traducción. Tampoco teníamos manera de hacer seguimiento de las actividades a las que se pudieran estar dedicando en estos momentos, y que debía incluir a la mayor cantidad de lenguas posibles de las que se tradujo en el breve periodo de años en que el Seminario de Poesía y Traducción estuvo abierto en la Facultad de Filosofía y Letras de la UNAM para estudiantes de todas las carreras de Letras de la UNAM, incluidas clásicas y dramáticas, y que además contó con la asistencia de estudiantes de otras disci- plinas. Al hacer la selección para la invitación, más allá de la calidad comprobada de su participación en el seminario, la apuesta era casi a ciegas. En ese sentido, la diversidad de sus nuevos orígenes, es decir, de dónde estaban ahora y por lo tanto desde dónde regresaban, dio al grupo una nueva dinámica, muy distinta a la que se daba en clase. Así mismo, el hecho de que pertenecieran a distintas generaciones otorgaba perspectivas y tempos diferentes con respecto a su experiencia como estudiantes. Esto contribuyó a que el grupo que se formó desarrollara una dinámica nueva. No todos se conocían, ni sabían qué hacían los demás tampoco nosotros -, e hizo inimaginable la posibilidad de que lo que se presentara fuera la reunión nostálgica de un grupo de antiguos compañeros. Como se verá en las pequeñas biografías que incluimos, algunos están dedicados a cosas muy alejadas de la traducción y otros en cambio viven inmersos en actividades académicas. Por esa razón fue muy satisfactorio ver que todos los convocados aceptaran, y que lo hicieran de manera entusiasta. Quiero suponer que es una constatación de la calidad del Seminario, y de la validez de sus planteamientos, ver regresar a un grupo de desconocidos con el deseo de trabajar juntos en un proyecto en el que no sabían a dónde iban a parar y en el que tampoco iban a recibir ninguna gratificación económica. En ese sentido, todas y cada una participaron pro bono. Quiero hacer constancia de esto, y también decir que me siento orgulloso de que con todo y eso 
hayan querido participar. No es lo ideal por supuesto, que no se les haya podido retribuir, pero como director del proyecto les agradezco su generosa participación.

Una vez aceptado el proyecto, como grupo de investigación teníamos muy claro que nuestro objetivo era reunir a un grupo de antiguos participantes en el seminario para trabajar en grupo y, a partir de las traducciones que habían hecho en clase, regresar a ellas con el fin de convertirlas en poemas con la calidad suficiente como para ser publicados (es decir, pasar de los circuitos de la apreciación escolar a convertirse en hecho público). También que, a partir de ese trabajo en común, cada una de ellas iría a escribir un nuevo texto o si así lo prefería a regresar al que había hecho, para producir un ensayo igualmente publicable. Considerábamos que al cabo de un año tendríamos el material reunido para entregar un producto a la DGAPA y a la vez tener un libro terminado. Lo que no sabíamos, dada las diferentes condiciones de trabajo de cada uno de los participantes, es cómo iba a funcionar el trabajo en grupo. Para quienes no conocen estos procedimientos, los PAPIMES de la UNAM se echan a andar a principios del año, y dependiendo de la propuesta, están contemplados para terminarse al cabo de uno, dos o tres años. Dado que ya teníamos antecedentes de trabajo, consideramos que para cumplir con los objetivos del proyecto bastaba con un año. Nuestro proyecto, como ya dije, contemplaba tres apartados. Empezamos por un lado a trabajar con la Coordinación de Desarrollo Educativo e Innovación Curricular (CODEIC) y a través de ellos con el grupo de investigación de la Universidad de Groningen, en Holanda. Quiero agradecer aquí el apoyo que tuvimos de Patricia González Flores, Subdirectora de Innovación Educativa de la actual CUAIED,y de Pablo Valdivia de la Universidad de Groningen, quien nos encaminó en los primeros usos de la plataforma Perusall. Mientras esto se iba dando, Mariela Castañeda y yo empezamos a hacer la selección de los participantes y para fines febrero teníamos un grupo seleccionado. Lo que no sabíamos, como nadie en el mundo, era lo que se nos venía encima. En febrero tuvimos una primera reunión de trabajo con todos los participantes del PAPIME en las oficinas de la entonces COCEIC, hoy COAIEED,y todavía a mitad de marzo, justo antes de que comenzara el encierro que aún en parte vivimos, nos reunimos en dichas oficinas por segunda y, no sabíamos, última vez. En esa ocasión todavía no llevábamos tapabocas.

Para esta parte del proyecto hicimos una selección que incluyó un número representativo de las lenguas que se tradujeron en clase. Como ya señalé, no pusimos como condición que se dedicaran a la investigación o a la enseñanza, ni a la creación o a la traducción. Tampoco teníamos la menor idea de qué manera los había afectado su paso por el seminario, cuál podría ser su reacción ante una convocatoria de este tipo y qué resultados traería, en caso de que se quisieran integrar al grupo. Sabíamos que 
los resultados de este proyecto irían a forma parte de los materiales de una investigación más amplia sobre la enseñanza de la traducción de poesía. Buscábamos realizar un trabajo de doble cuerda. Recordemos que estamos hablando de una investigación sobre la enseñanza de la traducción de poesía, y como tal tiene que mostrar resultados ostensibles. Su realización es el proceso mismo, y en ese sentido no importa si sus conclusiones son negativas o positivas. Desde esa perspectiva este libro es un «producto», es decir el resultado de una investigación que se tuvo que entregar y del cual se informó a sus patrocinadores, en este caso la DGAPA. Sin embargo, la otra cuerda de este trabajo, la que buscaba atar y bien atar sus resultados, contemplaba la reunión de un grupo de individuos talentosos capaces de sacar adelante un proyecto en común en el que cada uno de ellos iba a realizar su propio experimento: regresar a un poema traducido como ejercicio de clase, y a partir de ese trabajo escolar, que en su momento había obtenido una calificación curricular sobresaliente, pero no obstante escolar, convertirlo en un poema en español publicable, y hacer de su trabajo un ensayo literario. Con todo esto esperábamos, como coordinadores del proyecto y editores del libro, lograr la elaboración de un resultado elegante. Elegante en su sentido científico, es decir un instrumento de trabajo en donde las propuestas que se contemplan sobre la enseñanza de la traducción se expusieran con claridad, economía, limpieza y síntesis, pero elegante también en el sentido del arte, como un objeto que mostrara y presumiera de acabados poemas en español originados en otras lenguas, y de brillantes ensayos sobre tales poemas.

Para cuando por fin echamos a andar el grupo de investigación, ya todos estábamos encerrados, cada uno en donde le tocó estar. Esa situación que, como a todo el mundo, condicionó la manera en la que trabajamos de entonces en adelante, en el caso de este proyecto fue un bálsamo para todos y cada uno de los participantes. Durante esos primeros tres meses de la cuarentena, cuando no teníamos claro lo que se nos venía encima y todos íbamos como perdidos en el espacio, el ancla común del proyecto nos ayudó a continuar acompañándonos en nuestro quehacer cotidiano y en muchos casos significó el sentido principal de nuestra semana. Digamos que el saber que estábamos en un proyecto común y que este proyecto tenía una finalidad y un término nos sacó del marasmo en que nos percibíamos y nos hizo sentir que íbamos todos en un mismo barco, no hundidos en un generalizado naufragio. No entendíamos, cada uno de nosotros, en dónde estábamos en nuestras propias vidas, así que reunirnos, cada uno desde su cápsula espacial, para trabajar juntos fue a la vez reconfortante y emocionante. Íbamos, cada uno en su sillón Voltaire, a una velocidad vertiginosa, rodeando el planeta Traducción, prestos a aterrizar cuando llegara el momento, para entonces encaminarnos cada uno en la segunda parte de 
este viaje, es decir en la expedición individual que significaba la redacción del ensayo que acompañaría al poema traducido.

Yo recuerdo la emoción que me dio el primer día de trabajo, empezando apenas a entender cómo funcionaba la plataforma de zoom a la que los habíamos convocado desde la recién abierta página para académicos de la CUAED y tener en pantalla 24 o 32 cuadritos con imágenes que se movían de cada uno de ellos. Verlos a todos ahí, habiendo aceptado subirse a un proyecto que quizás en ese momento ni les iba ni les venía fue constatar que lo que había querido sembrar en el Seminario (valga la redundancia) había dado sus frutos. No voy a hacer aquí la narración de cómo fue todo este proceso. Mariela Castañeda, quien dio seguimiento al grupo en general y arropó a cada uno de los participantes, lo cuenta mucho mejor que yo. Sólo quiero añadir, en un texto que se ha extendido más de lo pensado, que me imagino esos meses de trabajo como un viaje en una nave espacial en el que cada uno de los miembros de la tripulación sabía cuál era su función, y también que, sin la participación de todos, esta nave no habría llegado a su destino. Y si bien no soy adicto a La guerra de las galaxias ni a ninguna otra serie de ciencia ficción, sí que he visto no pocas películas en las que se cuentan tales viajes. Así que así me sentía, feliz de reunirme cada semana durante unas horas a trabajar juntos, cada uno en su pantalla y todos para uno. Tuvimos incluso nuestra primera experiencia cercana del COVID, por suerte no traumática. Una de las participantes dejó de aparecer y al cabo de un par de semanas, cuando regresó, nos contó a todos cómo una reunión de trabajo en presencia física (prefiero usar esta expresión porque el adjetivo «presencial» también se puede aplicar a lo que sucede en zoom - ¿o es que ahí no hay presencia o no se está presente?) una persona asintomática había contagiado a todo el grupo. Dos semanas de ausencia, vistas como pueden ser las cosas, significó que su regreso fuera toda sonrisas y alivio. Y para el grupo fue un gusto tenerla de regreso.

La segunda etapa del proyecto, luego de revisar los poemas en grupo, fue trabajar de manera individual con cada uno de ellos. Ya todos habíamos aterrizado y tuvimos una última reunión para despedirnos e iniciar la siguiente etapa de la expedición cada uno por su cuenta. Nos habíamos acompañado varias semanas y ahora tocaba seguir su expedición de manera individual. Salimos de nuestras cápsulas y nos encaminamos por el planeta Traducción, cada uno con su propio bagaje, a escribir sus ensayos. Sin Mariela Castañeda, y Paulina Severo quien además de participante se había incorporado como becaria para hacer el seguimiento de los proyectos individuales, la compañía con la que me embarqué en esta nueva etapa del viaje, ahora convertidos en equipo de mando y tripulación para iniciar el proceso de edición, no habríamos sacado adelante esta segunda etapa de nuestro apren- 
dizaje, ahora de formación netamente profesional. Se trataba de dar acabado a cada uno de los ensayos con vistas a su publicación. A diferencia de lo que sucede en el medio editorial anglosajón, donde hasta para publicar un libro de poemas el editor tiene la última palabra sobre título, orden e incluso qué poemas se incluyen y cuáles no, en el ámbito del español esta función editorial no está del todo establecida, en detrimento, me atrevo a decir, de la calidad final de muchos libros. Quisiera saber de algún poeta en México que acepte que un desconocido llegue y le diga cómo debe salir su libro. Así de lamentables son muchas veces los resultados. En este caso, una vez terminada la revisión y discusión en grupo de los poemas, empezamos a trabajar de manera individual en la edición de los ensayos. Para ese momento, hacia el mes de junio de 2000, las cosas en los ámbitos familiares y de trabajo se habían, mal que bien, asentado, lo cual cambió el formato de trabajo. Ahora ya sin fecha semanal fija, y acomodándonos a los horarios de trabajo de los distintos integrantes del internado, las reuniones se volvieron individuales. Fuimos viéndonos Mariela, Paulina y yo con cada uno de ellos, algunos días en sesiones maratónicas de varias horas, otros con en sólo una reunión de una hora, hasta que terminamos de revisar todos y cada uno de los ensayos individuales. Lo que siguió ya fue una cuestión técnica, también de aprendizaje pero no menos importante para dar acabado a un proceso profesional de edición, en que tuvieron que solicitar derechos de autor, permisos de publicación, etc. Pero eso lo cuenta mejor Mariela Castañeda en su contribución a este libro.

\section{Rengas de taifas y hongos}

Borges iniciaba su breve - y a la vez dilatada en sus repercusiones - reflexión sobre las traducciones de Homero, publicada por primera vez en 1932 en Discusión, con las palabras con las que a su vez terminaba Magrelli su propia reflexión a partir de la rima, de lo que es esencial en un poema a la hora de traducirlo. Me permito traerlo de nuevo a colación porque apunta a cosas vitales no en los estudios de traducción sino en los de literatura: »ningún problema tan consustancial con las letras y con su modesto misterio como el que propone una traducción» (Borges, 1996: 252). No voy a extenderme ya más en los recovecos y laberintos gubiales que la traducción excava en la aparente claridad significativa de eso que llamamos literatura. Ya suficiente espacio le dediqué aprovechando las junturas y resquicios del ensayo de Antonio Alatorre. Pero quiero cerrar este ensayo con una reflexión ya apuntada sobre la enseñanza de la traducción, aunque ahora en términos un poco más generales. No quiero dejar de apuntar la nota obvia de que las traducciones homéricas (iy el ensayo de Borges!) deberían ser tema natural de estudio de las letras clásicas, como lo puede mostrar el desliz que el modesto misterio de la traducción de la Odisea, al ser hecha por 
una mujer, adelanto, introduce o muestra en el poema homérico. Emily Harris, la primera en traducirla al inglés, ha logrado por ejemplo dar un matiz a la dubitación adolescente de Telémaco que hasta donde yo sé ningún traductor antes había hecho notar, y que lo vincula sorpresivamente con Hamlet - esta última observación, aclaro, es mía (cf. Homer, 2017). Y aunque ella misma, cuando dice en un ensayo sobre el tema, que «Una se podría preguntar si el género de quien traduce hace una diferencia que puede ser notada en la página», no deja de observar que, independientemente de sus intenciones, «Las mujeres traductoras se sitúan muchas veces a una distancia crítica al acercarse a autores que no sólo son hombres, sino que además están profundamente imbricados en un canon que por muchos años ha sido imaginado como perteneciente a los hombres» ${ }^{21}$ (Wilson, 2017). Como se puede ver, éste es un tema que concierne a los estudios de traducción, de letras clásicas y de género.

De igual manera, los textos de Enrique Díez Canedo sobre traducción, por dar otro ejemplo, o las reflexiones de Tomás de Iriarte con las que inicié este ensayo, son muestra no sólo de lo relevante, sino de lo indispensable que debería ser contemplar los alcances significativos de la traducción en los estudios de Letras Hispánicas. Es cierto que las reflexiones de Borges sobre traducción aparecen salpicadas aquí y allá a lo largo de su obra, y no centradas en un solo libro en particular, como sus Nueve ensayos dantescos, por ejemplo. Lo mismo sucede con T. S. Eliot, que frente al indudable anuncio publicitario de su ensayo «Dante», no tiene ninguno que en el título recoja el tema de la traducción. Pero en ambos, si los vamos recorriendo espaciosamente, veremos que su reflexión se extiende por todos los campos que tocan el tema dela traducción. En ambos casos, si las espigáramos veríamos que, con todo lo insondables como intrincadas que son sus reflexiones, el lugar que le dan en su pensamiento sobre la escritura literaria es primordial. Para ver qué tan hondo cala pensar en traducción, hay que recurrir a los dobleces y mandobles del ensayo de Walter Benjamin sobre poesía y traducción en «La tarea del traductor», que podría situarse en el campo de la filosofía, o a los muchos ensayos que a partir de ahí han derivado, como las reflexiones de Paul de Man, que tocan la historia y la pedagogía (cf. Benjamin, 1923; Man, 1086). La traducción, podemos darnos cuenta, crece como los hongos. Pero pareciera que esto no pasa por las cabezas de quienes enseñan las literaturas del español. Las reflexiones sobre traducción que se han hecho a lo largo de la historia, tan sólo en español, nos darían no sólo material suficiente para todo

\footnotetext{
${ }^{21}$ «Female translators often stand at a critical distance when approaching authors who are not only male, but also deeply embedded in a canon that has for many centuries been imagined as belonging to men».
} 
un curso regular sino para ver, que es lo que realmente importa, hasta donde trasmina su influencia en la historia cultural de un país, de una lengua, de una literatura.

En ese sentido, uno de los fines de este libro ha sido mostrar cómo el intercambio y la variedad de perspectivas enriquecen tanto la formación como el desarrollo profesional de quienes estudian en la Facultad de Filosofía y Letras de la UNAM, y lo importante que sería que los seminarios de las distintas áreas se inseminaran (perdón de nuevo por la reiteración) unos a otros. Menciono esto porque lo contrario ha pasado con el Seminario de Poesía y Traducción, que ha ido viendo cómo se reduce su campo de acción. Como se muestra en este libro, el seminario ha sido rico en perspectivas y en proposiciones venidas de los campos de estudio sobre literatura que se imparten en la Facultad y en otros ámbitos de la UNAM, como la Escuela Nacional de Lingüística y Traducción, sin embargo en los últimos semestres ha visto reducido no su campo de influencia sino el acceso de los estudiantes que pudieran estar interesados en inscribirse y participar. Primero se canceló hace un par de años en el Colegio de Letras Hispánicas con el argumento de que «la traducción no es un área prioritaria para los estudios de literatura en español» (sic). Posteriormente el Colegio de Letras Clásicas también lo canceló con el argumento de que la lectura de textos en inglés, francés, italiano o alemán era demasiada carga de trabajo para quienes estudian Letras Clásicas. Finalmente, desde el semestre pasado, se me hizo saber que el Seminario sólo debería estar abierto para alumnos de Letras Inglesas, excluyendo a cualquier estudiante interesada que perteneciera a las otras literaturas del Colegio de Letras Modernas. Más que censuras concertadas, me parece que estas coincidencias simultáneas responden a dinámicas de enseñanza reduccionistas y particularizantes que, por supuesto, van en contra de lo que el campo de acción de la traducción, y su investigación extendida, proponen,y de lo que debería ser la enseñanza de las humanidades, así en plural.

En este momento el seminario está abierto exclusivamente a alumnos de Letras Inglesas, pues esas son las instrucciones que se me han dado. La rica pluralidad que progresivamente había ido teniendo se ha visto reducida por decisiones administrativas discrecionales revestidas de autoridad colegiada (pues son las comisiones académicas de los respectivos Colegios las que han tomado estas decisiones) al estudio de la traducción del inglés al español, lo cual es contrario a la propia naturaleza de la enseñanza de la traduión que propongo, centrada no en una lengua de salida y otra de meta, como si fueran carreras entre la liebre y la tortuga sino, como señalé al principio, extendida en la lengua en que resurge un poema, viniendo de donde sea, y que en este caso es el español. Mientras los responsables de los estudios en las distintas literaturas no vean la importancia de la traducción en sus respectivas disciplinas, y sigan sin darse cuenta de 
que el intercambio de materias es enriquecedor para la formación de las estudiantes, seguirán rechazando su relevancia y por lo tanto su estudio, aduciendo que el estudio de la traducción literaria pertenece a ese despicable grupo de asignaturas que se alejan de los conocimientos esenciales de la literatura. Fíjense por dónde, no tanto la reflexión sobre la traducción sino la realidad tangible, me ha llevado, casi de la mano, a señalar lo importante que es que las disciplinas del área de Humanidades tengan vías de comunicación y contacto. Ese fue el centro de mi propuesta cuando fui candidato a dirigir la Facultad hace poco más de cuatro años. Sigo pensando lo mismo: mientras las estructuras académicas se ejerzan para imponer límites a quienes no son parte de un colegio o congregación determinadas, o para beneficiar discrecionalmente esta o aquella tendencia por encima de otras perspectivas menos unilineales, y mientras no se fomente la enseñanza basada en la práctica, los estudios de humanidades van a estar cada vez más parcelados, más pulverizados y la pérdida tanto de calidad intrínseca como de relevancia externa van a seguir creciendo.

Voy a terminar con dos ejemplos venidos no de la traducción sino de los estudios aviarios. En un libro en el que relata su experiencia personal en cetrería, la escritora inglesa Helen Macdonald cuenta que la manera en que los pinzones aprenden a cantar es escuchando a otros pinzones. Por eso, dice, «los pinzones silvestres tienen distintos dialectos sonoros, dependiendo de la región en la que viven» (Macdonald, 2014: 65). ${ }^{22}$ Lo interesante, lo que podemos aprender de su ejemplo es que el umbral, o la ventana, o la luz de aprendizaje de los pinzones es de una duración muy corta. Los polluelos tienen necesidad de escuchar el canto de otros pinzones para articular el suyo propio, que será semejante al de sus vecinos, aunque a la vez tendrá características propias. Pero si por alguna razón no tienen contacto con otros pinzones, su trino va a ser desarticulado, roto, ni siquiera limitado, y para acabar pronto nunca van a aprender a cantar. En cambio, si tienen acceso a esas otras voces dispares, es resultado no es uniforme y las diferencias varían: puede su canto incluso, dice Macdonald, ser más delgado, menos complicado de una región a otra. Es decir que si los pinzones que cantaban en Surrey tenían un trino más elaborado, se debía a lo que habían escuchado de otros pinzones. Helen es poeta e historiadora de la ciencia en la Universidad de Cambridge, como mi amigo Carlos López Beltrán, que también estudió allá, y con quien me embarqué en estas tareas alrededor de la traducción de poesía, a las que he dedicado mucha de mi enseñanza. Algo similar ocurre con los ruiseñores, quienes, según el saxofo-

22 «Wild chaffinches from different places had different dialects». 
nista y ornitólogo David Rothenberg, son capaces de interactuar con los sonidos producidos por los humanos (cf. Rothenberg, 2019: 10). En mi propio caso, puedo decir que lo que yo aprendí, en las clases con Antonio Alatorre pero también con Graciela Cándano o con el filósofo Eduardo Nicol o con el sociólogo Daniel Bell, he tratado de dárselo a mis alumnos. El resultado de este aprendizaje es lo que aparece en este libro. Digamos que tuve la suerte de tener ventanas de enseñanza tan enriquecedoras como diversas. La pequeña anécdota tomada del libro de Macdonald me sirve para imaginar que a pesar de cambios y reducciones siempre habrá ventanas de aprendizaje en las que se encuentre espacio para replicar. En ese sentido, no puedo no ver este libro sino como un multifamilar, y agradecer a todas y cada uno de quienes iluminaron sus propias ventanas para dejarnos ver lo que adentro de ellas pasa. Y para cerrar, y sin salirme de la ornitología regresar al tema de la traducción de poesía y los resultados de su enseñanza abierta, quiero insinuar la lectura en parábola del siguiente poema de Matthew Sweeney, un poeta irlandés al que Carlos López Beltrán y yo tradujimos, y presentarla sólo en español, para de esta manera, con un ejemplo tangible, mostrar que este poema pertenece a la literatura en español, y más concretamente a la historia de la literatura mexicana del siglo XX, que fue cuando se hizo. No obsta añadir que para poder publicarlo aquí tuve que pasar por las mismas tareas de cartas y peticiones que los demás participantes en este libro han tenido que pasar, lo cual no deja de darme un cierto regusto de felicidad. Por esa razón y con esa intención quiero dedicar su publicación aquí, estén haciendo lo que estén haciendo, a todas aquellas personas que asistieron al Seminario de Poesía y Traducción, mientras duró.

¿No es una locura que María renunciase así al aviario y se fuese a Jamaica? ¿Te la imaginas sin aves y sin jaulas ni llaves, rodeada de negritos? No escuchas la marea y ese olor entre brea y café con ganjá? ¿Qué es eso en la postal que mandó en navidad? ¿No pasó cinco años con aves de mil tamaños a las que detestaba? ¿O era acaso la jaula y no los bichos de alas el blanco de su furia? ¿O esa tela de alambre que encajonaba el aire y que lo parcelaba? $Y$ tener que barrer tanta pluma, tanta hez un día y luego el otro. Y mira ahora a María confusa en su alegría lo morena que está. Escúchale la risa extraña y quebradiza, piensa en la pobre niña. Imagina, ¿voló 
desde Heathrow

para llegar allá?

Enviemos del aviario

un pequeño canario

con las alas cortadas.

Que se acuerde María

de cómo eran sus días

aquí, y que sea feliz. ${ }^{23}$

\section{Bibliografía}

\section{Impresa}

Alatorre, A. (2012). Lingüística y literatura. Em: A. Alatorre. Ensayos sobre crítica literaria. (Ed. corregida y aum.). El Colegio de México. México;

Ballard, M. (1992). De Ciceron à Benjamin. Traducteurs, traductions, réflexions. Presses Universitaires de Lille. Lille;

Benjamin, W. (1971). La tarea del traductor. En: Angelus Novus. (Trad. de Héctor Álvarez). Barcelona. Edhasa;

Bonnefoy, Y. (1990). Entretiens sur la poésie. Mercure de France. Paris;

Borges, J. L. (1996). Las versiones homéricas, Obras completas. Emecé, Buenos Aires. Vol. 1;

Briggs, K. (2017). This Little Art. Fitzcarraldo Editions. Londres;

Eliot, T. S. (1978). Reflections on Vers Libre. To Criticize the Critic. Faber \& Faber. London;

Eliot, T. S. (2015). East Cocker. En: The Poems of T. S. Eliot. Johns Hopkins University Press. Baltimore. Vol. 1;

Ellrodt, R. (2006). Comment traduire poésie. Palimpsestes, hors série: 65-75;

González Iglesias, J.A. (2016). El Arte poética de Horacio y algunas líneas anticlásicas de la cultura contemporánea. Minerva - Revista de Filología Clásica, 29: 23-44;
Hofmann, M. (2013). Introduction. En: Gottfried Benn, Impromptus. Selected Poems and some Prose. Farrar, Straus and Giroux. Nueva York; Homer (2017). The Odyssey. (Trad. de Emily Wilson). Norton. Nueva York;

Horacio (1998). XX odas del libro III. (Trad. de Daniel Samoilovich y Antonio D. Tursi). Hiperión. Madrid;

Horacio (2021). Arte poética. (Introd., trad., notas y comentario de Juan Antonio González). Cátedra. Madrid;

Iriarte, T. de (1777). El Arte poética de Horacio o Epístola a los pisones. Imprenta Real de la Gaceta. Madrid;

Kutik, I. (2005). Russian «monuments»: Theses and reflections. Cardinal Points, 5: 126-141;

Lampert, C. (2015). Frank Auerbach. Speaking and Painting. Thames \& Hudson. London;

Longley, M. (1995). The Ghost Orchid. Jonathan Cape. London;

Love, A.C. (2021, 26 de enero). Chance, evolution, and the meaning of the burgess shale fossils. Apresentado en el Philosophy of Biology Circle Meeting;

Polizotti, M. (2018). Sympathy for the Traitor. A Translation Manifesto. The MIT Press. Cambridge;

Macdonald, H. (2014). H is for Haw. Jonathan Cape. London;

Man, P. (1986). Conclusions: Walter Benjamin's «The Task of the Translator». En: The Resistance to Theory. Manchester University Press. Manchester;

Rothenberg, D. (2019). Nightingales in Berlin. Searching for the Perfect Sound. The University of Chicago Press. Chicago;

Salas Salgado, F. (2012). «Arte poética» de Horacio, en la traducción de Tomás de Iriarte (1777). Em: F. Lafarga e L. Pegenaute. Cin-

${ }^{23}$ Matthew Sweeney. El aviario (Trad. de Carlos López Beltrán y Pedro Serrano). 
cuenta estudios sobre traducciones españolas. Peter Lang. Berna;

Venuti, L. (1997). The Translator's Invisibility. A History of Translation. Routledge. London;

Verhesen, F. (2003). A la lisière des mots. Sur la traduction poétique. La Lettre Volée. Bruselas.

\section{Digital}

Crist, M. (2018, 25 de octubre). Race doesn't come into it. London Review of Books. 40(20). Accedido el 3 de diciembre de 2021, en: https://www.lrb.co.uk/the-paper/v40/n20/ meehan-crist/race-doesn-t-come-into-it;

Fondebrider, J. (2020,16 de diciembre). Un diálogo de sordos [Versión electrónica]. Buenos Aires Poetry. Accedido el 3 de diciembre de 2021, en: https://buenosairespoetry. com/2020/12/16/un-dialogo-de-sordos-jorge-fondebrider/;
Género (s. d.). Diccionario del español de México. Colegio de México. México. Accedido el 3 de diciembre de 2021, en: https://dem.colmex. $\mathrm{mx} / \mathrm{ver} / \mathrm{g} \% \mathrm{C3} \% \mathrm{~A} 9$ nero;

Magrelli, V. (2016). Una quartina de Yves Bonnefoy e qualque paradosso. Tradurre, 10. Accedido el 3 de diciembre de 2021, en: https:// rivistatradurre.it/esercizi-di-rima/;

Monge, E. (2021, 29 de marzo). Twitter. Accedido el 3 de diciembre de 2021, en: https:// twitter.com/MongeEmiliano/status/137 6563006662963205;

Wilson, E. (2017, 7 de julio). Found in translation: how women are making the classics their own. En: The Guardian. Accedido el 3 de diciembre de 2021, en: https://www.theguardian.com/books/2017/jul/07/women-classics-translation-female-scholars-translators. 